\title{
The Canadian Benign Prostatic Hyperplasia Audit Study (CanBas)
}

\author{
J. Curtis Nickel, MD; ${ }^{*}$ Joe Downey, MSc; ${ }^{*}$ Francois Bénard, MD; ${ }^{\dagger}$ Michael Chetner, MD; ${ }^{\dagger}$ \\ John Grantmyre, MD; ${ }^{\text {s }}$ Alan So, MD;/ Paul Whelan, $M D^{* *}$
}

\begin{abstract}
Objective: To determine the prevalence, diagnostic patterns and management of lower urinary tract symptoms (LUTS) associated with benign prostatic hyperplasia (BPH) in Canadian urology outpatient practice.

Methods: Representative urologists were randomly selected from lists provided by the Canadian and Quebec Urological Associations. Each patient identified with a BPH diagnosis during a typical 2-consecutive-week period during April, May or June 2007 was asked to complete a corresponding International Prostate Symptom Score (IPSS) questionnaire. Each day, the participant urologist completed an outpatient log and a detailed programmed chart review to transcribe demographics, investigations and treatments associated with each $\mathrm{BPH}$ patient.
\end{abstract}

Results: Eighty-six urologists were invited to participate. Thirty-eight (44.2\%) agreed, and 27 of those $(71.1 \%$ ) submitted evaluable data for the audit. Of the 5616 patients seen in outpatient practice (average 208 per urologist), 4324 $(77 \%)$ were male. A BPH diagnosis was identified in $19.6 \%$ of the men $(n=849$; mean age 69.5, standard deviation [SD] 10, yr; age range 40-100 yr; mean duration of symptoms 4.8, SD 4.2, yr; mean IPSS score 12.3, SD 7.4; mean prostate specific antigen [PSA] 3.9, SD 3.9, ng/mL). Twenty-four percent of patients had prostates that were rated as large, $50 \%$ as medium and $26 \%$ as small. PSA level correlated positively with prostate volume. Twenty-two percent were initial consultations for LUTS and $78 \%$ were repeat visits. Diagnostic evaluation tended to follow those examinations and tests recommended by the Canadian $\mathrm{BPH}$ guidelines. Treatment choices tended to follow an evidence-based algorithm with respect to treatment choices for men in the various prostate-volume and PSA groups.

Conclusion: This prospective audit indicates that BPH remains a common condition managed by urologists in outpatient practice. Investigations and treatments confirm that Canadian urologists appear to be following Canadian BPH guidelines as well as the most recent evidence from the literature.

CUAJ 2008;2(4):367-73

\section{Introduction}

Lower urinary tract symptoms (LUTS) associated with benign prostatic hyperplasia (BPH) are regarded as a common problem managed by urologists. The severity of LUTS and a fear of prostate cancer result in referrals to urologists, but it is the degree of bother, interference with activities, decreased quality of life and, in some cases, complications of $\mathrm{BPH}$, that drive men to seek treatment. Initial investigations are designed to determine the severity of LUTS and the degree of bother, the risk of prostate cancer, and the presence or absence of complications of BPH (e.g., retention, stones, infection, obstructive uropathy). Further parameters are evaluated to determine the risk of progression in terms of symptoms, acute urinary retention or the need for BPH-related surgery, and to assist in the actual treatment choice. The Canadian Guidelines for the Management of Benign Prostatic Hyperplasia, published in 2005, outline the recommended diagnostic and therapeutic algorithms that are indicated for the management of BPH in Canada. Subsequent prospective treatment studies such as CombAT $^{2}$ and PROACT, ${ }^{3}$ in which Canadian clinical researchers played a major role, have confirmed many of the recommendations made in the guidelines, particularly those related to medical therapy.

Information on urological practice patterns in relation to managing LUTS or BPH in Canada is scarce. In 2000, Ramsey and colleagues ${ }^{4}$ published the results of 1995 and 1998 questionnaire surveys in an attempt to determine how Canadian urologists managed $\mathrm{BPH}$ in the 1990s. This survey not only suffered from all the real limitations and inaccuracies of a retrospective questionnairebased survey, but it was also conducted before many of the major BPH clinical trials (e.g., Medical Therapy of Prostatic Symptoms $[\text { MTOPS }]^{5}$ ) were available and before either the 2003 American $^{6}$ or 2005 Canadian' ${ }^{1}$ BPH guidelines were developed. In 2004, Nickel and Saad' examined the attitudes of Canadian urologists regarding the transposition of the US BPH guidelines into Canadian urological practice. It was this perspective that led to the development of Canadian BPH guidelines. ${ }^{1}$ Have the guidelines and recent clinical trial data impacted Canadian urological practice? Except for 
Nickel et al.

pharmaceutical company marketing surveys, notorious for their inaccuracy, to our knowledge, these data are not available. Our prospective practice audit was designed to determine the prevalence, diagnostic patterns and management of men identified with a clinical diagnosis of BPH in Canadian urology outpatient practice.

\section{Methods}

\section{Synopsis}

This was a descriptive, prospective urology outpatient audit carried out in a representative sample of Canadian urologists over a 2-consecutiveweek period during April, May or June 2007.

\section{Subjects}

Potential participants (all urologists) were determined from lists provided by the Canadian and Quebec Urological Associations. Each potential candidate was put into categories of geographic area (east, Quebec, Ontario and west), sex and type of practice (university, community). Participants were randomly selected from each category so that a representative $10 \%$ participation was ensured for each particular category. Urologists were reimbursed for their participation. All instructions, forms, documents and consents were available in English and French. The study was approved by the Queen's University Ethics Review Board and was compliant with Canadian privacy legislation.

\section{Study design}

The randomly chosen urologists were invited to participate in the trial. Participating urologists chose a representative 2-consecutive-week period in April, May or June 2007 to complete their audit. Each patient with a clinical diagnosis of BPH (past or present diagnosis) was asked to complete the International Prostate Symptom Score (IPSS). At the end of each study day, the urologists completed a daily outpatient log sheet, noting the total number of male and female patients seen in outpatient clinics that particular day. For each patient identified with a diagnosis of $\mathrm{BPH}$, the urologist completed a Canadian Benign Prostatic Hyperplasia
Audit Study (CanBas) data card outlining the patient's age, sex, diagnosis, duration of symptoms, whether this was a repeat or initial visit, diagnostic tests (any documented test that had been performed in the past and any diagnostic test performed or ordered during the current visit) and treatments (any documented treatment that had been performed in the past and any treatment performed or planned during the current visit). The patient's most recent prostate specific antigen (PSA) level was noted, and urologists were asked to estimate prostate volume as small $(<30 \mathrm{~mL})$, medium $(\geq 30 \mathrm{~mL}$ and $<50 \mathrm{~mL}$ ) or large $(\geq 50 \mathrm{~mL})$, and indicate how the volume was measured (digital rectal examination or transrectal ultrasonography).

\section{Analysis}

Outpatient practice logs, questionnaires and CanBas data cards were sent to the Queen's University, Department of Urology data centre for analyses. The outpatient logs were tabulated to determine the prevalence of $\mathrm{BPH}$ diagnoses, whereas the CanBas data cards and questionnaires were analyzed to determine patient characteristics, diagnostic patterns and treatment strategies associated with a BPH diagnosis in urology outpatient practice.

Descriptive statistics, Student $t$ test analysis and $z$ test proportional analysis were calculated with SigmaStat 3.1 statistical software (Aspire Software International).

\section{Results}

Eighty-six urologists were invited to participate in the study. Thirty-eight (44.2\%) agreed, and 27 of those $(71.1 \%)$ completed the audit. Figure 1 shows the distribution of those urologists who were invited, who accepted and who completed the audit. Sixty-three percent (17) of the participants were community urologists; $37 \%$ (10) were practising in an academic institution. Ninety-six percent of the urologists (26) were male; $4 \%$ (1) were female.

A total of 5616 patients (4324 [77\%] men) were seen in outpatient urology practice over the 2-week audit period (average 208 per urologist). Eight-hundred forty-nine of the men were diagnosed with BPH (average 31.4 per urologist, range 4-131). Table 1 describes the demographics and baseline characteristics of the men identified with a $\mathrm{BPH}$ 
diagnosis. The patients' mean symptom score was 12.3 (SD 7.4) (14, SD 7.3, for the 190 new consultations and 11.8, SD 7.3, for the 659 repeat patients). Table 2 shows the most common investigations performed (or planned at that particular visit) for men diagnosed with BPH. Overall, urinalysis and PSA were the most common tests performed, followed closely by flow rate and residual urine determination, cystoscopy and urine culture. Intravenous pyelography was the least ordered test in this survey. Table 3 shows the treatments prescribed to these patients (previous, ongoing and ordered during that particular visit). As expected, the most common treatments are medical therapies (with $\alpha$-blockers, 5 - $\alpha$ reductase inhibitors [5-ARIs] and combination therapy, ranked in that order) followed by transurethral resection of the prostate. Table 4 shows medical therapy documented at the current visit ( $\alpha$-blockers, 5-ARIs and combination therapy) stratified according to volume of prostate and PSA level.

\section{Discussion}

The CanBas prospective audit study confirms the significant prevalence of $\mathrm{BPH}$ in outpatient practice (1 man in 5). Diagnostic testing appears to be compatible with the Canadian BPH guidelines, ${ }^{1}$ which describe history, physical examination and urinalysis as mandatory assessments in the diagnosis of BPH. Based on examination of retrospectively collected data from past visits and prospectively collected data from the current visit, it is apparent that a digital rectal examination and urinalysis was performed for most patients. A formal symptom inventory and PSA are recommended evaluations in the guidelines. Since every BPH patient was asked to complete an IPSS, the proportion of urologists who administer such a symptom inventory is unknown. During an initial visit for BPH, most patients had their serum PSA tested (interestingly, about $65 \%$ had a urinalysis and PSA documented before the initial consultation). As

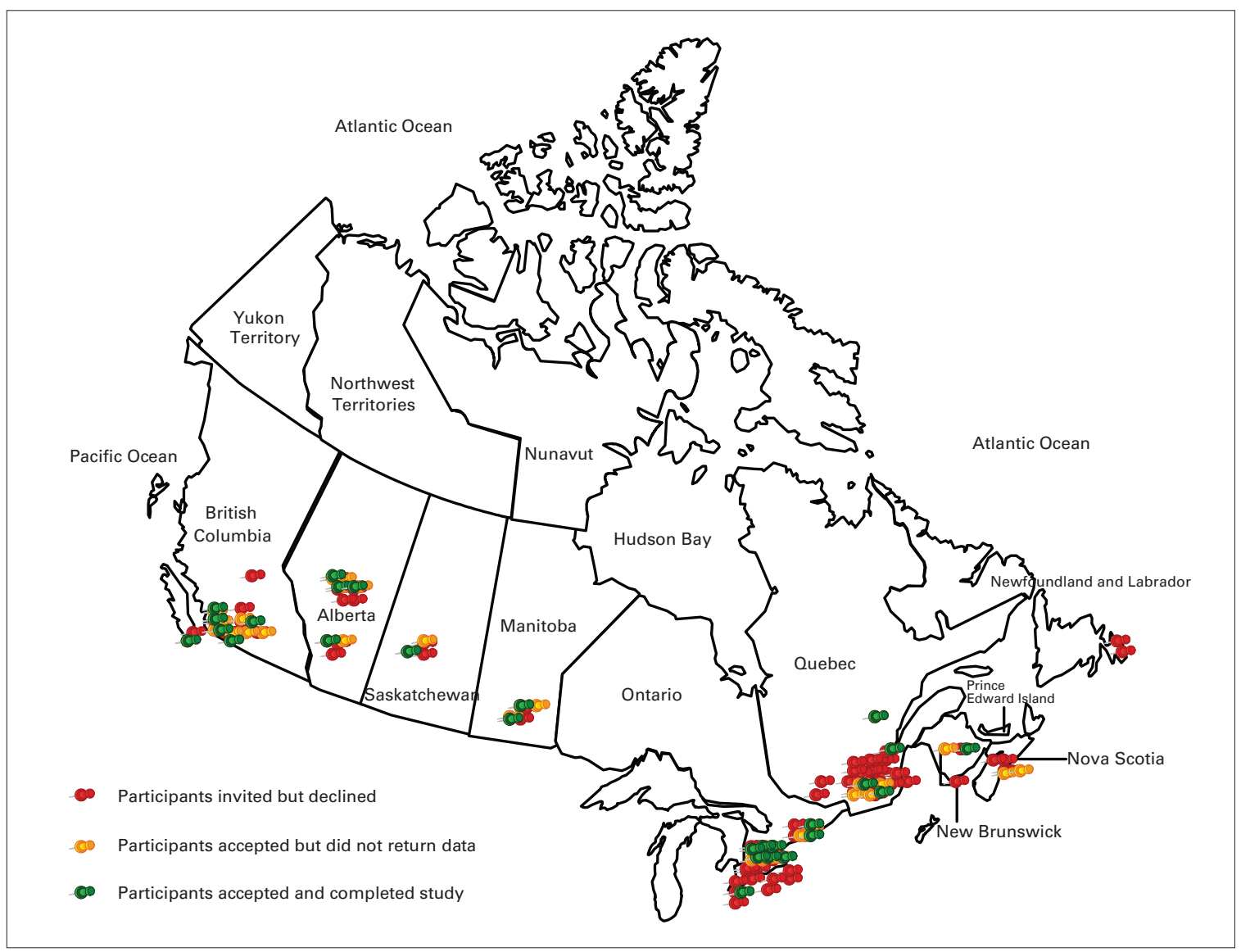

Fig. 1. Geographic distribution of Canadian Benign Prostatic Hyperplasia Audit Study participants. 
Nickel et al.

expected, fewer patients had a urinalysis or PSA ordered for them when seen for a repeat visit.

Optional tests in the $\mathrm{BPH}$ guidelines include flow rate and residual urine determinations, and about one-third of BPH patients either had the examination in the past or it was ordered during the

Table 1. Demographics and characteristics of patients identified with a diagnosis of benign prostatic hyperplasia

\begin{tabular}{|c|c|c|c|c|c|c|c|c|c|c|}
\hline \multirow[b]{3}{*}{ Group } & \multicolumn{10}{|c|}{ Parameters, demographics and characteristics } \\
\hline & \multicolumn{3}{|c|}{ Patient age, yr } & \multirow[b]{2}{*}{$\begin{array}{l}\text { Duration of } \\
\text { symptoms, yr } \\
\text { (and SD) }\end{array}$} & \multicolumn{4}{|c|}{ Severity score } & \multicolumn{2}{|c|}{ Prostate volume*† } \\
\hline & $\begin{array}{c}\text { Mean } \\
\text { (and SD) }\end{array}$ & Median & Range & & $\begin{array}{c}\text { Mean } \\
\text { (and SD) } \\
\text { IPSS } \\
\text { score }\end{array}$ & $\begin{array}{l}\text { IPSS } \\
\text { range }\end{array}$ & $\begin{array}{l}\text { Mean } \\
\text { (and SD) } \\
\text { quality of } \\
\text { life score }\end{array}$ & $\begin{array}{l}\text { Quality } \\
\text { of life } \\
\text { score, } \\
\text { range }\end{array}$ & $\begin{array}{c}\text { No. (and } \\
\% \text { ) of } \\
\text { patients } \ddagger\end{array}$ & $\begin{array}{c}\text { Mean } \\
\text { (and SD) } \\
\text { PSA, } \\
n g / m L\end{array}$ \\
\hline $\begin{array}{l}\text { All BPH } \\
\text { patients } \\
(n=849)\end{array}$ & $69.5(10)$ & 69 & $40-100$ & $4.8(4.2)$ & $12.3(7.4)$ & $0-35$ & $2.3(1.5)$ & $0-7$ & - & - \\
\hline $\begin{array}{l}\text { New } \\
\text { consultations } \\
(n=190)\end{array}$ & $68.2(11)$ & 67 & $45-100$ & $2.4(2.4)$ & $14(7.3)$ & $0-33$ & $2.9(1.5)$ & $0-6$ & - & - \\
\hline $\begin{array}{l}\text { Repeat visits } \\
(n=659)\end{array}$ & $69.6(9.7) \S$ & 69 & 40-95 & 5.5 (4.3) & $11.8(7.3)$ & $0-35$ & $2.2(1.5)$ & $0-7$ & - & - \\
\hline $\begin{array}{l}\text { All prostate } \\
\text { volumes }\end{array}$ & - & - & - & - & - & - & - & - & 699 (100) & 3.9 (3.9) \\
\hline $\begin{array}{l}\text { Small } \\
\text { prostate }\end{array}$ & - & - & - & - & - & - & - & - & $206(25.7)$ & $2.5(2.9)^{* *}$ \\
\hline $\begin{array}{l}\text { Medium } \\
\text { prostate }\end{array}$ & - & - & - & - & - & - & - & - & $399(50)$ & $3.7(3.0)^{* *}$ \\
\hline $\begin{array}{l}\text { Large } \\
\text { prostate }\end{array}$ & - & - & - & - & - & - & - & - & 194 (24.3) & $6.0(5.4)^{* *}$ \\
\hline 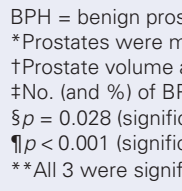 & $\begin{array}{l}\text { ic hyperplasia; IP } \\
\text { sured by digital re } \\
\text { PSA level were } \\
\text { patients with bot } \\
\text { t difference in ag } \\
\text { t difference in du } \\
\text { ntly different fron }\end{array}$ & $\begin{array}{l}S S=\text { Internati } \\
\text { ectal examinat } \\
\text { available for } 6 \\
\text { h prostate vol } \\
\text { e for initial v. } \\
\text { ration of symp } \\
\text { none another }\end{array}$ & $\begin{array}{l}\text { nal Prostate } \\
\text { on } 85.6 \% \text { of } t \\
9 / 848 \text { BPH pa } \\
\text { me and PSA I } \\
\text { epeat visits). } \\
\text { toms, initial v. } \\
p<0.05 \text {. }\end{array}$ & $\begin{array}{l}\text { Symptom Score; PSA = } \\
\text { he time and transureth } \\
\text { atients. } \\
\text { level documented. } \\
\text { repeat visits). }\end{array}$ & $\begin{array}{l}\text { prostate specific } \\
\text { al ultrasound } 14\end{array}$ & $\begin{array}{l}\text { antigen; SD } \\
4 \% \text { of the tir }\end{array}$ & $\begin{array}{l}=\text { standard deviat } \\
\text { ne. }\end{array}$ & & & \\
\hline
\end{tabular}

Table 2. Procedures documented in the past, or planned or performed during the current visit in 849 patients diagnosed with benign prostatic hyperplasia

\begin{tabular}{|c|c|c|c|c|c|c|}
\hline \multirow[b]{3}{*}{ Procedure } & \multicolumn{6}{|c|}{ Group; no. (and \%) } \\
\hline & \multicolumn{2}{|c|}{ All patients ( $n=849$ ) } & \multicolumn{2}{|c|}{ Initial visit $(n=190)$} & \multicolumn{2}{|c|}{ Repeat visit ( $n=659$ ) } \\
\hline & Past visit & $\begin{array}{l}\text { Current } \\
\text { visit }\end{array}$ & Past visit & $\begin{array}{l}\text { Current } \\
\text { visit }\end{array}$ & Past visit & $\begin{array}{c}\text { Current } \\
\text { visit }\end{array}$ \\
\hline Urinalysis & 619 (72.9) & $332(39.1)$ & $127(66.8)$ & $116(61.0)$ & $492(74.7)$ & 216 (32.8) \\
\hline PSA & $558(65.7)$ & $404(47.6)$ & $123(64.7)$ & $107(56.3)$ & $434(65.7)$ & $297(45.1)$ \\
\hline Cystoscopy & 329 (38.8) & $126(14.8)$ & 56 (29.5) & 56 (29.5) & 273 (41.4) & 69 (10.5) \\
\hline Urine culture & $324(38.2)$ & $118(13.9)$ & $71(37.4)$ & $39(20.5)$ & $253(38.4)$ & $79(12)$ \\
\hline Uroflow/residual & $281(33.1)$ & $229(27.0)$ & $48(25.3)$ & $57(30.0)$ & $233(35.4)$ & $172(26.1)$ \\
\hline Urodynamics & $42(4.9)$ & $23(2.7)$ & $7(3.7)$ & $13(6.9)$ & $35(5.3)$ & $10(1.5)$ \\
\hline TRUS & $172(20.3)$ & $41(4.8)$ & $36(19.0)$ & $14(7.4)$ & $136(20.6)$ & $27(4.1)$ \\
\hline Biopsy & $151(17.8)$ & $30(3.5)$ & $33(17.4)$ & $9(4.7)$ & $118(17.9)$ & $21(3.2)$ \\
\hline $\begin{array}{l}\text { Abdominal/pelvic } \\
\text { ultrasound }\end{array}$ & $127(15.0)$ & $18(2.1)$ & $29(15.3)$ & $7(3.7)$ & $98(14.9)$ & $11(1.7)$ \\
\hline IVP & $17(2.0)$ & $3(0.4)$ & - & $2(1.1)$ & $17(2.6)$ & $1(0.2)$ \\
\hline Cytology & $81(9.5)$ & $19(2.2)$ & $6(3.2)$ & $6(3.2)$ & $75(11.4)$ & $132.0)$ \\
\hline Other & $19(2.2)$ & $43(5.1)$ & $6(3.2)$ & - & $13(2.0)$ & $28(4.3)$ \\
\hline
\end{tabular}


current visit. The incidence of cystoscopy either performed in the past, or performed or planned during the current visit is interesting. Cystoscopy is not recommended in the guidelines unless there is an indication (e.g., hematuria, poor response to medical therapy, surgical planning). A cystoscopy was performed or planned during the initial visit for almost $30 \%$ of patients and $10 \%$ of patients seen for repeat visits. This would suggest that some urologists may still employ cystoscopy as a first-line diagnostic evaluation, although many of these patients likely had it for prescribed indications as listed above. But to put this into context, in the 2000 questionnaire survey, $39 \%$ of urologists indicated

\begin{tabular}{|c|c|c|c|c|c|c|}
\hline \multirow[b]{3}{*}{ Treatment } & \multicolumn{6}{|c|}{ Group; no. (and \%) } \\
\hline & \multicolumn{2}{|c|}{ All patients $(n=849)$} & \multicolumn{2}{|c|}{ Initial visit $(n=190)$} & \multicolumn{2}{|c|}{ Repeat visit ( $n=659)$} \\
\hline & Past visit & Current visit & Past visit & $\begin{array}{l}\text { Current } \\
\text { visit }\end{array}$ & Past visit & $\begin{array}{c}\text { Current } \\
\text { visit }\end{array}$ \\
\hline$\alpha$-Blockers & $477(56.2)$ & $437(51.5)$ & 63 (33.3) & $85(44.7)$ & $414(63.9)$ & $352(54.3)$ \\
\hline Monotherapy & Unknown* & 296 (34.9) & Unknown* & $64(33.7)$ & Unknown* & $229(34.7)$ \\
\hline $5-\alpha$ reductase inhibitors & $182(21.4)$ & $208(24.5)$ & $21(11.1)$ & $34(17.9)$ & $161(24.7)$ & $174(26.9)$ \\
\hline Monotherapy & Unknown* & $67(7.9)$ & Unknown* & $13(6.8)$ & Unknown* & $51(7.7)$ \\
\hline $\begin{array}{l}\text { Combination } \\
\text { ( } \alpha \text {-Blockers and } 5-\alpha \\
\text { reductase inhibitors) }\end{array}$ & Unknown* & $141(16.7)$ & Unknown* & $21(11.1)$ & Unknown* & $123(18.7)$ \\
\hline Anticholinergic & $41(4.8)$ & $42(4.9)$ & $2(1.1)$ & $8(4.2)$ & $39(6.0)$ & $34(5.2)$ \\
\hline Phytotherapy & $48(5.7)$ & $15(1.8)$ & $17(9)$ & $8(4.2)$ & $31(4.8)$ & $7(1.1)$ \\
\hline Antibiotics & $58(6.8)$ & $12(1.4)$ & $8(4.2)$ & $1(0.5)$ & $50(7.7)$ & $11(1.7)$ \\
\hline TURP & $101(11.9)$ & $37(4.4)$ & $13(6.9)$ & $10(5.3)$ & $88(13.6)$ & $27(4.2)$ \\
\hline Open prostatectomy & $3(0.4)$ & $1(0.1)$ & $1(0.5)$ & $0(0.0)$ & $2(0.3)$ & $1(0.2 .0)$ \\
\hline TUNA & $3(0.4)$ & $0(0.0)$ & $1(0.5)$ & $0(0.0)$ & $2(0.3)$ & $0(0)$ \\
\hline TUMT & $1(0.1)$ & $0(0.0)$ & $0(0.0)$ & $0(0.0)$ & $1(0.2)$ & $0(0)$ \\
\hline TUIP & $3(0.4)$ & $2(0.2)$ & $2(1.1)$ & $0(0.0)$ & $1(0.2)$ & $2(0.3)$ \\
\hline Laser & $1(0.1)$ & $0(0.0)$ & $0(0.0)$ & $0(0.0)$ & $1(0.2)$ & $0(0)$ \\
\hline Other & $27(3.2)$ & $40(4.7)$ & $4(2.1)$ & 10 (5.3) & $23(3.5)$ & $26(4.0)$ \\
\hline
\end{tabular}

\begin{tabular}{|c|c|c|c|}
\hline \multirow[b]{2}{*}{ Variable } & \multicolumn{3}{|c|}{ Treatment; no. (and \%) of patients } \\
\hline & $\begin{array}{c}\alpha-B l o c k e r \\
\text { monotherapy }\end{array}$ & $\begin{array}{l}\text { 5- } \alpha \text { reductase } \\
\text { inhibitor } \\
\text { monotherapy }\end{array}$ & $\begin{array}{c}\text { Combination } \\
\text { therapy } \\
\text { ( } \alpha \text {-blocker and } \\
5-\alpha \text { reductase } \\
\text { inhibitor) }\end{array}$ \\
\hline \multicolumn{4}{|l|}{ Prostate size $(n=790)$} \\
\hline Small $(n=205)$ & $83(40.5)$ & $9(4.4)$ & $20(9.8)$ \\
\hline Medium ( $n=394)$ & $145(36.8)$ & $27(6.9)$ & $55(14.0)$ \\
\hline Large $(n=191)$ & $46(24.1)$ & $28(14.7)$ & $60(31.4)$ \\
\hline \multicolumn{4}{|l|}{$\mathrm{PSA}, \mathrm{ng} / \mathrm{mL}(n=620)$} \\
\hline$<1.5(n=170)$ & 66 (38.8) & $8(4.7)$ & $23(13.5)$ \\
\hline$\geq 1.5$ to $<3.5(n=191)$ & $74(38.7)$ & $6(3.1)$ & 37 (19.4) \\
\hline$\geq 3.5(n=259)$ & $61(23.6)$ & $43(16.6)$ & $51(19.7)$ \\
\hline
\end{tabular}


Nickel et al.

that they employ cystoscopy as a primary diagnostic tool. ${ }^{4}$ It appears that the guidelines are beginning to influence practice patterns in this regard. Intravenous pyelography is not recommended in the guidelines, and in this audit, it was ordered in less than $1 \%$ of patients during the current visit. Transrectal ultrasonography is not recommended for prostate volume determination, rather in conjunction with a prostate biopsy. This audit would indicate that the guidelines are being followed since the incidence of transrectal ultrasonography very closely mirrors that of prostate biopsy.

The BPH guidelines strongly recommend medical therapy as first-line treatment, and our audit confirms medical therapy as the most common treatment for LUTS/BPH. Currently, 59\% of men seen in urological practice have been prescribed medical therapy (either prescribed during the current visit or maintained at the visit). Our audit further confirms that $\alpha$-blocker therapy was the most popular medical therapy $(51 \%$ of men were taking or had been prescribed an $\alpha$-blocker, and 35\% of the total were on $\alpha$-blocker monotherapy). 5-ARI therapy was used less often as monotherapy and more likely as combination therapy, presumably for increased efficacy (currently 25\% were taking or had been prescribed 5-ARI therapy, either as monotherapy or combination therapy). The Canadian $\mathrm{BPH}$ guidelines suggest that combination therapy is more effective than monotherapy and should be considered for men with large prostate glands and higher levels of serum PSA. Evidence from the Proscar Long-term Efficacy and Safety Study $(\mathrm{PLESS})^{8}$ shows that finasteride provides the most efficacy in patients with larger prostates $^{9}$ and higher PSA levels. ${ }^{10}$ Furthermore, the MTOPS 5 analysis concludes that combination therapy is superior to either $\alpha$-blocker or finasteride monotherapy and shows the most efficacy compared with placebo in terms of both symptom improvement and reduction in risk of progression in patients with large prostates and high PSA levels. ${ }^{11}$ The preliminary 2-year symptom assessment analysis from CombAT ${ }^{2}$ confirms the increased efficacy of combination therapy with dutasteride and tamsulosin but further shows that over a 2-year period, the 5-ARI provides as much or more symptom amelioration than the $\alpha$-blocker in selected patients with PSA greater than $1.5 \mathrm{ng} / \mathrm{mL}$ and prostate volume greater than $30 \mathrm{~mL}^{2}$ In the present CanBas audit, there is a definite trend toward 5-ARI monotherapy and combination therapy in men with larger prostates and higher PSA levels. Combination therapy is being prescribed in $10 \%, 14 \%$ and $31 \%$ in men identified with small, medium and large prostates, respectively, while $13 \%$ of men with PSA of less than $1.5 \mathrm{ng} / \mathrm{mL}$, compared with almost $20 \%$ of men with a PSA of $1.5 \mathrm{ng} / \mathrm{mL}$ or greater, were prescribed combination therapy. The Canadian urology opinion sur$v^{2} y^{7}$ done before the development of the Canadian $\mathrm{BPH}$ guidelines suggested that many Canadian urologists added a 5-ARI to an $\alpha$-blocker if and when desired efficacy was not achieved or was lost. Data from the Symptom Management After Reducing Therapy (SMART) ${ }^{12}$ study and the recently published PROACT ${ }^{3}$ suggests that after 6-9 months of combination therapy, the $\alpha$-blocker can be safely discontinued while dutasteride and finasteride, respectively, are continued in most patients with no subsequent decrease in efficacy. A limitation of data collection in this audit does not allow analysis of the past sequence of $\alpha$-blocker and 5-ARI use, so that introduction of 5-ARI and (or) discontinuation of the $\alpha$-blocker as a management strategy cannot be determined. However, it is apparent that the prevalence of men in urological practice who are on 5-ARI monotherapy increases with increasing prostate volume and PSA level $(4 \%, 7 \%$ and $15 \%$ for small, medium and larger prostates, respectively; $3 \%-5 \%$ and $17 \%$ for $\mathrm{PSA}<3.5 \mathrm{ng} / \mathrm{mL}$ and $\geq 3.5 \mathrm{ng} / \mathrm{mL}$, respectively).

There are a number of limitations in this type of practice audit. Symptoms cannot be correlated with treatment decisions since the symptoms themselves are affected by ongoing treatment. In fact, symptom severity documented in repeat visits is less than that documented in the initial visit, likely reflecting therapeutic intervention. Similarly, PSA (and perhaps prostate volume) will be affected by 5 -ARI therapy. This is probably the reason a number of men with a PSA level of less than $1.5 \mathrm{ng} / \mathrm{mL}$ continue on $5-\mathrm{ARI}$ and combination therapy (PSA may have been $>1.5 \mathrm{ng} / \mathrm{mL}$ when the treatment decision was made). Other limitations include the low response rate to the initial invitation, but $71 \%$ of those who agreed to participate did in fact complete the 2-week audit and the distribution was reasonably representative. A selection bias of urologists may have occurred because, although physicians were randomly invited to participate in the study, urologists submitting 
data may not be as random since they chose to participate (they are perhaps more interested in $\mathrm{BPH})$. One of the strengths of our study is that this was not a typical retrospective questionnaire in which participants answered how they believe they should practise. Rather, this audit documented how they actually practised. The number of participants and documented $\mathrm{BPH}$ patients provided a sufficient sample size to determine associations, trends and patterns.

Appropriate management and resource use for LUTS/BPH will become major challenges for the health care system because of the aging of our population and increased life expectancy. This, together with the change noted in our study from primarily surgical procedures to medical therapy as the first-line management approach for LUTS/BPH, means that knowledge of how we practise is important. Data from this practice audit complement data from randomized clinical trials by providing clinicians, researchers and policy-makers with information on the actual implementation and effect of clinical trial evidence and guidelines in the "real-life" clinical practice of managing BPH patients. The data from our study suggest that the Canadian urological community is practising a guideline-recommended, evidence-based approach to the diagnosis and treatment of $\mathrm{BPH}$.

From *Queen's University, Kingston, Ont., the †University of Montréal, Montréal,

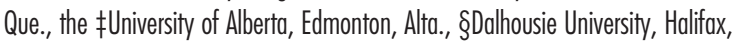
NS, the qUniversity of British Columbia, Vancouver, BC, and ${ }^{\star *}$ McMaster University, Hamilton, Ont.

Funding: This study was funded by an independent investigator initiated research grant to J. Curtis Nickel from the Merck Frosst Inc. University Grants Program.

This article has been peer reviewed.
Competing interests: None declared.

\section{References}

1. Nickel JC, Herschorn S, Corcos J, et al. Canadian Guidelines for the Management of Benign Prostatic Hyperplasia. Can I Urol 2005;12:2677-83.

2. Roehrborn CG, Siami P, Barkin J, et al. Effects of dutasteride, tamsulosin and combination therapy on lower urinary tract symptoms in men with benign prostatic hyperplasia and prostatic enlargement: 2-year results from CombAT study. J Urol 2008; 179: 616-21.

3. Nickel JC, Barkin J, Koch C, et al.; PROACT Investigators. Finasteride monotherapy maintains stable lower urinary tract symptoms in men with benign prostatic hyperplasia following cessation of alpha blockers. CUAJ 2008;2:16-21.

4. Ramsey EW, Elhilali M, Goldenberg GS, et al.; Canadian Prostate Health Council. Practice patterns of Canadian urologists in benign prostatic hyperplasia and prostate cancer. J Urol 2000;163:499-502.

5. McConnell JD, Roehrborn CG, Oliver OM, et al.; MTOPS Research Group. The long term effect of doxazosin, finasteride and combination therapy on the clinical progression of benign prostatic hyperplasia. N Engl J Med 2003;349:2385-96.

6. AUA Guidelines on management of benign prostatic hyperplasia (2003). Chapter 1: Diagnosis and treatment recommendations. J Urol 2003;170:530-47.

7. Nickel IC, Saad J. The American Urological Association 2003 Guidelines on Management of Benign Prostatic Hyperplasia: a Canadian opinion. Can J Urol 2004;11:2186-93.

8. McConnell JD, Bruskewitz R, Walsh P, et al. The effect of finasteride on the risk of acute urinary retention and the need for surgical treatment among men with benign prostatic hyperplasia. N Engl J Med 1998;338:557-63.

9. Roehrborn CG, Boyle P, Bergner D, et al. Serum prostate-specific antigen and prostate volume predict long-term changes in symptoms and flow rate: results of a four-year, randomized trial comparing finasteride versus placebo. Urology 1999;54:662-9.

10. Roehrborn CG, McConnell JD, Lieber M, et al. Serum prostate - specific antigen concentration is a powerful predictor of acute urinary retention and need for surgery in men with clinical benign prostatic hyperplasia. PlESS Study Group. Urology 1999. 53:473-80.

11. Roehrborn CG. Definition of at-risk patients: baseline variables. BJU Int 2006;97 (Suppl 2): 7-11.

12. Barkin J, Guimaraes $M$, Joacobi $G$, et al. Alpha-blocker therapy can be withdrawn in the majority of men following initial combination therapy with the dual 5alpha-reductase inhibitor dutasteride. Eur Urol 2003;44:461-6.

Correspondence: Dr. J. Curtis Nickel, Professor of Urology, Queen's University, Canada Research Chair in Urologic Pain and Inflammation, Department of Urology, Kingston General Hospital, Kingston ON K7L 2V7; icn@queensu.ca 